\title{
O QUE E QUEM NÃO É UBUNTU: CRÍTICA AO “EU” DENTRO DA FILOSOFIA UBUNTU
}

\section{WHAT IS NOT UBUNTU: CRITICISM OF SELF WITHIM UBUNTU PHILOSOPHY}

\author{
Luís Augusto Ferreira Saraiva ${ }^{1}$ \\ Recebido em: 07/2019 \\ Aprovado em: 09/2019
}

\begin{abstract}
Resumo: O presente trabalho tem como objetivo fazer uma investigação sobre o conceito de Ubuntu, a partir de uma crítica ao desuso habitual que vem ocorrendo em nosso campo linguístico sobre sentido do termo. Para isso, recorremos ao cenário de discurso da (s) Filosofia (s) africana (s) para compreender os aspectos Epistemológicos, Ontológicos e Éticos de Ubuntu, sem fugir das reflexões da Linguagem. Ubuntu se traduz em um conceito de Humanidade que em constante debate se opõe ao conceito de Humanidade trago pela modernidade, tal reflexão visa criticar a tradicional forma de que se traduziu Ubuntu, Eu sou porque nós somos, em que percebemos uma espécie de antecedência do "Eu" sobre a comunidade. Para essas, abordagens retomamos o filósofo Ramose, teórico em destaque sobre Ubuntu, como um norteador deste debate, não lançando mão, também, de críticas ao autor.
\end{abstract}

Palavras-Chave: Epistemologia. Ética. Filosofia Africana. Ontologia. Ubuntu

\begin{abstract}
This paper aims to make an investigation about the concept of Ubuntu, from a criticism to the usual disuse that has been occurring in our linguistic field about the meaning of the term. For this, we resort to the discourse scenario of African Philosophy (s) to understand the Epistemological, Ontological and Ethical aspects of Ubuntu, without escaping the reflections of Language. Ubuntu translates into a concept of Humanity that in constant debate is opposed to the concept of Humanity brought by modernity, such reflection aims to criticize the traditional way that translated Ubuntu, I am because we are, in which we perceive a kind of advance of "Me" about the community. For these approaches, we take up the philosopher Ramose, a prominent theorist about Ubuntu, as a guide for this debate, not resorting to criticism of the author.
\end{abstract}

Keywords: Epistemology. Ethic. African philosophy. Ontology. Ubuntu

\section{Introdução}

A Filosofia Ubuntu se compõe enquanto uma parte da Filosofia Africana, ou melhor,

\footnotetext{
${ }^{1}$ Doutorando em Bioética (UnB). Mestre em Metafísica (UnB). Especialista em História e Cultura Afro-Brasileira e Africana (UFG). Especialista em Relações étnico-raciais, gênero e diferenças no contexto do ensino de História e Cultura brasileiras (UFMS). Licenciado em História (UFMA). Licenciado em Filosofia Faculdade Santa Fé FSF. Bacharelando em Letras Francês Tradução (UnB). E-mail: luisferrarafilos@gmail.com
} 
das Filosofias Africanas, posto que o tão vasto continente apresenta um caráter plural em meios aos assuntos étnicos, políticos e culturais africanos. Neste sentido nossa intenção é apresentar a Filosofia Ubuntu enquanto uma perspectiva singular do pensamento africano de origem Bantu$^{2}$ que acentua o conceito de humanidade. E é sobre este conceito de humanidade apresentado pela Filosofia Ubuntu é que se torna possível compreender as experiências-mundo que compõem o quer segundo Aguessy (1980) podemos chamar de Proprium Africanum. Entretanto, o que se pretende no decorrer deste texto é entender como o conceito de Ubuntu se compõe enquanto uma Filosofia Complexa ao nosso entendimento, tendo em vista a nossa compreensão de mundo por vias da Colonização e da Modernidade e que foge das dicotomias ontológicas cartesianas, tendo em vista que “As Meditações Filosóficas” (1641) de René Descartes, se construíram enquanto a base e fundamentação do conhecimento de todo o Novo Mundo.

Ainda, por vezes, podemos analisar em um cenário mais recente no constante ao uso da palavra Ubuntu desassociada do seu verdadeiro sentido, isto, significa uma perda habitual do seu sentido lexical e semântico que está contido na própria ideia de Ubuntu. Isto pode ser analisado na recorrente tradução da palavra Ubuntu que ganhou bastante espaço dentro do nosso vocabulário, que seria “Eu sou porque nós somos”. O $\boldsymbol{E} \boldsymbol{u}$, que aqui aparece destacado é o centro de nossa crítica, onde compreendemos que esta tradução que supostamente reflete a ideia de Ubuntu é em algum momento a negação e afastamento da compreensão do ser africano e seu sentido de mundo, isto, ao tomarmos como ponto inicial de nossa reflexão o víeis investigativo da Filosofia Africana.

Por assim dizer, seria necessário falar de "Filosofias Africanas" ao invés de "Filosofia Africana", pois, como tal sabemos o tão amplo continente não é o território de apenas um único povo em específico, e sim um espaço que abriga diversas culturas, em suas mais variadas complexidades, que de tal modo cada cultura tem a sua própria e particular percepção sobre o mundo.

Entretanto, antes de abordarmos mais profundamente sobre a Filosofia Ubuntu e consequentemente a nossa crítica sobre o $\boldsymbol{E} \boldsymbol{u}$ propomos estabelecer rápida uma reflexão sobre a Filosofia Africana, ou melhor, sobre Filosofia(s) Africana(s) - não seja uma forma de justiçar sua existência ou não, mas toma-la como tal para a construção e elaboração de conceitos - onde,

\footnotetext{
${ }^{2} \mathrm{O}$ tronco de Bantu inclui uma infinidade de etnias que, do ponto de vista geográfico, estão estendidas da linha do equador até o fim do Cabo da Boa Esperança. Em suas línguas vernáculas, o termo muntu significa pessoa e seu plural, Bantu, pessoas. A investigação das várias formas de manifestação de sua existência levou à descoberta de sua filosofia. (ONDÓ, 2001. p.158)
} 
é assumir um posicionamento político antirracista e anti-epistemicista a fim de advogar pela legitimidade do pensamento de pessoas negras do continente africano e da diáspora, onde estes tiveram sua humanidade subalternizada ao ponto de serem excluídas da História Universal.

A Filosofia Africana é uma denúncia ao anonimato causado pela História ao longo do tempo que silenciou o aparato intelectual dos grupos étnicos africanos; este silenciamento foi causado pelo eurocentrismo ${ }^{3}$ à luz da dominação e da exploração que entendia a Europa como "o modelo da humanidade, da cultura e da história em si mesma" (EZE, 2001. p. 55). Entretanto, mesmo com a situação pela qual os negros africanos passavam no período da colonização, suas percepções sobre o mundo não deixaram de estarem evidentes, os diversos entendimentos sobre o mundo atravessaram o Atlântico através da memória, os saberes aprendidos e difundidos em África permaneceram presentes e obtiveram outros espaços. Logo, a(s) Filosofia(s) Africana(s) possui em seu cerne o caráter da permanência, sendo que mesmo com a experiência da colonização o espírito filosófico se manteve presente na construção de diálogos orais entre África e o Novo Mundo.

Portanto, a Filosofia Africana se concentra em uma reflexão que aborda todo um conjunto de análises de sistemas tradicionais e contemporâneos, que fazem pensar sobre crenças e valores, concebendo a vida como um bem maior.

Ainda, ao se tratar de Filosofia Africana não podemos separar mitos e imaginários, religião e política, e outros aspectos sociais que se comportam como alicerces fundamentais da Filosofia Antiga e Contemporânea em África.

Se para tal modo entendermos a Filosofia como uma parte essencial pertencente a humanidade, temos então um novo modo de pensar a filosofia, tendo como ponto de partida a intenção de agregar diferentes maneiras de atingir o conhecimento. Sendo assim, segundo Omoregbe

A filosofia é fundamentalmente uma atividade reflexiva. Filosofar é refletir
sobre a experiência humana em busca de respostas, diferentes perguntas
fundamentais. [...] A experiência humana é a fonte da atividade reflexiva
conhecida como filosofia. Esta experiência poderá ser do homem sobre si
mesmo (subjetividade) e deste com o mundo que o rodeia (objetividade). ${ }^{4}$

${ }^{3} \mathrm{O}$ meu argumento é que esta realidade é tão verdadeira hoje como era no período colonial. O pensamento moderno continua a operar mediante linhas abissais que dividem o mundo humano do sub-humano, de tal forma que princípios de humanidade são postos em causa por práticas desumanas. As colónias representavam um modelo de exclusão radical que permanece atualmente no pensamento e práticas modernas ocidentais tal como aconteceu no ciclo colonial. (SANTOS, 2010. p. 39).

${ }^{4}$ La filosofía es fundamentalmente una actividad reflexiva. Filosofar es reflexionar sobre la experiencia humana en busca de respuestas, varias preguntas fundamentales. [...] La experiencia humana es la fuente de la actividad reflexiva conocida como filosofía. Esta experincia pudiera ser la del hombre sobre sí mismo (subjetividad) o la de 
(OMOREGBE, 2002. p. 19)

A posição de Omoregbe sobre a filosofia reflete sobre a ideia que a própria filosofia está atrelada intrinsecamente a humanidade. Logo, é a experiência humana o lugar em que habitam as formulações de conceitos dos quais sobrevive a Filosofia. $\mathrm{O}$ ato de filosofar sugere o desenvolvimento de uma potencialidade reveladora do mundo que nos possibilita entender que o conhecimento não é apenas uma regalia do Ocidente, mas que todo ser humano existente possui o direto (e a capacidade) de refletir sobre si e sobre a própria natureza.

\section{Algumas Reflexões Criticas da Filosofia Ubuntu}

O título deste artigo, em um primeiro momento, parece soar estranho a quem já tenha ouvido falar ou ler alguma coisa sobre a Filosofia Ubuntu que vem tomando espaço de grande destaque nos últimos anos. Entretanto a imagem que Ubuntu tem tomado no Ocidente tem sido apresentada com vias de exotização e deturpação, ainda, a Filosofia Ubuntu tem sido confundida com uma filosofia da harmonia, sinônimo de autoajuda e de auto sucesso empreendedor que sustenta as atuações do mundo corporativista.

Imagens estas sobre Ubuntu, consequentemente, correspondem a uma lógica do mercado global que promove a competição entre os indivíduos e sustenta o esvaziamento das ideias africanas. Ainda, o sentido que Ubuntu ganhou nos meios sociais que se utilizam dessa Filosofia como pauta norteada de suas ações parece satisfazer uma aparência de atitudes individualizadas de solidariedade. Logo, a atual imagem de Ubuntu parece ter se tornado o slogan da compaixão ao ponto de suplantar a ideia de humanidade que consiste na palavra. Não se pode entender Ubuntu como uma linha de pensamento que defende que as diferenças não possam existir e nem tão pouco possa haver conflitos entre elas.

Outro fator que nos faz discordar das imagens sobre Ubuntu que são veiculadas hoje é a propagação de Ubuntu como a totalidade da Filosofia Africana em geral, Ubuntu como falamos no início é uma experiência particular da concepção Bantu da realidade. Não podemos identificar Ubuntu como um conceito pertencente a todo o continente africano e intuir que a Filosofia Africana se resumiria somente a Ubuntu ou que Ubuntu seria a síntese de toda a Filosofia Africana.

A apropriação que o Ocidente fez e faz sobre a Filosofia Ubuntu tem sido uma estratégia

éste con el mundo que lo rodea (objetividad). (Texto Original) 
do racismo afim de novamente reduzir as formas de pensamento do continente africano tratando-as apenas como folclóricas e enquadrá-las em um estágio "pré-racional”.

Este tipo ação é visto sobre a mais comum narrativa sobre Ubuntu que encontramos:

Um antropólogo estava estudando os usos e costumes de uma tribo na África $e$, quando terminou seu trabalho, teve que esperar pelo transporte que o levaria até o aeroporto de volta pra casa. Sobrava muito tempo, mas ele não queria catequizar os membros da tribo, então, propôs uma brincadeira para as crianças, que achou ser inofensiva.

Comprou uma porção de doces e guloseimas na cidade, colocou tudo num cesto bem bonito com laço de fita e deixou o cesto debaixo de uma árvore. Chamou as crianças e combinou que quando ele dissesse "já!", elas deveriam sair correndo até o cesto e, a que chegasse primeiro ganharia todos os doces que estavam lá dentro.

As crianças se posicionaram na linha demarcatória que ele desenhou no chão e esperaram pelo sinal combinado. Quando ele disse "Já!", instantaneamente todas as crianças se deram as mãos e saíram correndo em direção à árvore com o cesto. Chegando lá, começaram a distribuir os doces entre si e a comerem felizes. $O$ antropólogo foi ao encontro delas e perguntou porque elas tinham ido todas juntas se uma só poderia ficar com tudo que havia no cesto e, assim, ganhar muito mais doces. Elas simplesmente responderam: "Ubuntu, tio. Como uma de nós poderia ficar feliz se todas as outras estivessem tristes?" Ele ficou de cara! Meses e meses trabalhando nisso, estudando a tribo, e ainda não havia compreendido, de verdade, a essência daquele povo. Ou jamais teria proposto uma competição, certo? ${ }^{5}$

Esta parábola que popularizou a palavra Ubuntu carrega sem si uma carga de estereótipos sobre o continente africano. Tal narrativa se constitui enquanto um exemplo dramático que representa uma visão limitada sobre Ubuntu repara-se que a fábula inicia com a saga de um antropólogo, não identificado, que estar a estudar os costumes de uma "tribo" o que deixa em evidência, segundo a narrativa, o caráter de atraso e de não desenvolvimento dos povos habitantes em África. Outro ponto a ser criticado é a não especificação da "tribo", que novamente apresenta a imagem de uma África cheia de "tribos" e que necessitam do contato com a civilização.

Contundo, outro equívoco que a narrativa parece apresentar é que; ora, se é uma "tribo africana", como se concentra a fábula, que tipos de ações movimentam as crianças a querem doces? Ao que se demonstra, é uma troca injusta e exploratória que novamente a presença do colonizador na figura do antropólogo clássico se manifesta na tarefa de extrair mentalidades "primitivas" e objetificantes sobre os povos tradicionais africanos. Crítica esta que escreve Castiano quando a colonização se pôs a colher os saberes que possuíam os sujeitos africanos:

\footnotetext{
5 Texto Retirado do Site http://www.espacoubuntu.com.br/a-filosofia.html. Acessado em 24/12/2017.
} 
O Saber destes informantes está, de certeza por aí espalhado ou com nota de rodapé. Esses velhos e jovens informantes foram objectificados, ou seja, tornados objectos embora na sua condição de sujeitos do conhecimento. Dito de outra forma, eles nunca foram apresentados como sujeitos do seu saber sendo-lhes reservado o lugar de aparecem como ilustrações (em forma de fotos), como "provas" da autenticidade das informações contidas nos Usos e Costumes e noutros escritos divulgados por antropólogos missionários e coloniais. (CASTIANO, 2010. p. 35)

As crianças, segundo nossa interpretação da tendenciosa fábula, não são apresentadas como sujeitos do conhecimento, mas sim como aportes para a conclusão do trabalho do antropólogo, logo, caso não fosse o antropólogo da narrativa, Ubuntu não seria reconhecido no ocidente. $\mathrm{O}$ fato é que esta narrativa que tem sido fortemente utilizada por programas motivacionais de empresas que estimulam seus empregados a conquistarem mais lucros, nada tem a ver com Ubuntu.

Tais compreensões sobre Ubuntu não satisfazem a origem da palavra e nem tão pouco ao seu sentido filosófico, tendo em vista, que Ubuntu não tem a ver com apenas cordialidade como está sendo lindo atualmente, mas que se trata de meios de manutenção da vida coletiva. Viver em coletivo na medida em que o humano se dá por meio da comunidade interconectada com o mundo.

Em oposição a tais imagens que tentam resumir o conceito de Ubuntu, podemos perceber que filosofia Ubuntu enfatiza o conceito de humanidade, humanidade para com a comunidade, em uma não referenciarão ao eu individualista moldado pela modernidade. Ubuntu busca se referir a tudo que é humano e a tudo que partilha da força vital estabelecendo relação interrelacional de importância fundamental pela existência das pessoas, pelo que se percebe: "É assim a força, com sua misteriosa presença, que proporciona a possibilidade de classificar os seres numa hierarquia que compreende todos os domínios existentes: mineral, vegetal, animal, humano, ancestral e divino". (MUDIMBE, 2013. p. 175).

Cada pessoa é a representatividade de uma parte da humanidade, que, em sua totalidade, habita nela. Além disso, Ubuntu remete ao movimento que precede a existência, novamente uma existência anterior ao eu, é uma dinâmica de interfaces da própria existência. Logo, tudo que é existe faz parte da humanidade.

Ubuntu é a "categoria fundamental ontológica e epistemológica do pensamento africano dos falantes da língua Bantu” (RAMOSE, 2002. p.02.), como também ética que expressa a noção de humano veiculada a uma concepção de humanidade interconectada a tudo que age, 
que come que respira tenha e seja Ubuntu, é também "uma crítica contra a visão simplista e interesseira" (MALOMALO, 2004. p. 99). Isto nos faz entender que há uma dificuldade de se traduzir para qualquer outra língua o que é Ubuntu de fato. Logo, até que ponto a mais corrente tradução de Ubuntu "Eu sou porque nós somos" consegue definir e expressar o conceito de humanidade? Onde estaria o $\boldsymbol{E} \boldsymbol{u}$ ? Sendo que para este determinado tronco linguístico ${ }^{6}$ dentre as línguas Xhosa, Zulu e Swati, "que habitam o território da África do Sul, o país de Mandela" (MALOMALO, 2004. p. 95). Não há uma única só referência em que se apresente a noção do “Eu” Ocidental que é tão importante para o Ocidente.

Ora, seria correto afirmar uma anterioridade do "eu” em relação à comunidade? Para a tentativa de tradução de Ubuntu por: "Eu sou porque nós somos”, o “Eu” apresenta-se sempre como um agenciamento anterior ao "nós". Este tipo de deslocamento condiciona a afirmação de uma posição de destaque individualista perante própria comunidade que antecede aos seres humanos. No entanto, se a perspectiva Ubuntu está atrelada há uma humanidade coletiva que se constrói na força vital compartilhada e produzida pelo "nós", onde então estaria o lugar do "outro" em um mundo onde tudo é "nós"?

Ao que nos parece, tal reflexão nos leva a perceber que a primazia dos "nós" abrange uma linguagem dinâmica e fluida sobre a comunidade, tendo em vista que este mesmo "nós" com categoria em si também compartilha de uma pluralidade das experiências de mundo que existem nas diversas comunidades. Por conseguinte, para se entender Ubuntu como uma filosofia do entendimento de humanidade e do cuidado mútuo, é necessário perceber que para que o os seres existam na/em comunidade há sempre uma anterioridade lógica, histórica e ontológica que compõem os seres.

Em outras palavras, a comunidade é sempre anterior ao “ $\boldsymbol{E} \boldsymbol{u}$ ” Ocidental, de tal maneira que conseguimos repensar as relações de existência e coexistência dos seres humanos para com a comunidade. Para Mudimbe, ao tratar sobre natureza da comunidade Bantu, onde aparece a palavra Ubuntu, "A comunidade destaca-se e compreende-se como uma entidade natural e social e infere autoridade do seu ser e da sua história" (MUDIMBE, 2013. pp. 188-189). Isto gera um sentimento de pertencimento e partilha da experiência de estar no mundo.

Sendo assim, nossa intenção se concentra em pensar Ubuntu como uma perspectiva humanitária que seja crítica às imagens estereotipadas desta parte do pensamento Bantu. Ainda,

\footnotetext{
6 “As línguas da família Bantu são faladas nos Camarões, parcialmente no gabão, Guiné Equatorial, Congo, Cabinda, Zaire, Angola, Ruanda, Burundi, Tanzânia, Zâmbia, Malawi, Moçambique, Suazilândia, Lesoto, Bostswana, Zimbabué, África do Sul e Namíbia” (Mudimbe, 2013. P. 183)
} 
a percepção de humanidade compartilhada faz recorrer a ancestralidade e a memória como componentes da própria comunidade, ao passo, para qualquer ser exista dentro da comunidade. É necessário saber que já há uma história que nos antecede, nos fazendo saber que a partir do momento em que entendemos como as comunidades são feitas, nos ajuda a saber quem somos.

Surge então a prerrogativa de fazer um mergulho histórico na palavra Ubuntu e averiguar as terminologias de seu uso, afim de fugir de imagens exotizantes para decodificar o seu real sentido enquanto uma categoria filosófica que se traduz na experiência comunitária do "nós" a qual compartilha a existência com todas as outras existências.

\title{
Ubuntu enquanto ética filosófica
}

Ainda, sobre a nossa investigação sobre a Filosofia Ubuntu podemos entender como aponta, Ondó que "A linguagem Bantu é uma linguagem essencialmente metafísica, é uma linguagem que aponta diretamente para a essência das coisas 7" (ONDÓ, 2001. p. 159); nesse sentido, Ubuntu possui seu "fundamento de ser procurado na Ontologia, na Epistemologia e na Ética" (CASTIANO, 2010. p. 156), como também uma maneira singular de lidar com a natureza das coisas e que por sua vez, traz uma nova imagem sobre os seres humanos.

Os aprofundamentos teóricos sobre Ubuntu passam a ser destacados por Ramose que "começa por querer demonstrar que o ubuntu é a base ou fundamento da filosofia africana" (CASTIANO, 2010. p. 156). Segundo este filósofo sul-africano

\begin{abstract}
Ubuntu é a raiz da filosofia africana. A existência do africano no universo é inseparavelmente ancorada sobre ubuntu. Semelhantemente, a árvore de conhecimento africano deriva do ubuntu com o qual é conectado indivisivelmente. Ubuntu é, então, como uma fonte fluindo ontologia e epistemologia africana. Se estas últimas forem as bases da filosofia, então a filosofia africana pode ser estabelecida em e através do ubuntu. (RAMOSE, 1999. p. 1, grifos meu)
\end{abstract}

Assim, em sua percepção ética de Ubuntu Ramose reconhece que a existência do ser africano está correlacionada ao seu posicionamento moral para com o universo. Onde o “conceito e experiência está ligado epistemologicamente a umuntu. Com base nesta ligação, umuntu postula ubuntu como sua categoria normativa básica da ética”. (RAMOSE, 2001. p. 1). Sendo umuntu "a emergência do homo loquens, que é simultaneamente um homo sapiens. Em

\footnotetext{
7“"El lenguaje bantú es un lenguaje esencialmente metafísico, es un lenguaje que apunta directamente a las esencias de las cosas. (Texto Original)
} 
uma linguagem coloquial, significa o ser humano: o criador de política, religião e lei” (RAMOSE, 1999, p. 2). Ainda, este princípio de emergência humana presente na esfera de valores éticos possui também sua relação com o restante da realidade (ONDÓ, 2001. p. 162).

Esta precedência umuntu "revela outra característica fundamental do Ubuntu dos seres humanos" (NASCIMENTO, 2016. p. 237), onde há o aparecimento de uma linguagem definidora da existência humana, que permite o agenciamento da comunicação a partir de ações inter-relacionais no espaço onde a palavra também possui força vital. Este umuntu, "como o resto dos demais animais, nasce, se desenvolve e morre. Seu princípio vital é dobrado [...] cuja união constitui Ubuzima (união do corpo com a alma)"8 (ONDÓ, 2001. p. 162). Esta dinâmica da linguagem consegue produzir uma comunicação abrangente sobre a totalidade da realidade, isto faz com que a ética Ubuntu se concentre em uma conexão de relações de pessoas consigo e com outras pessoas dentro da comunidade por meio do Ntu que "é o denominador comum que aparece em todos os seres. O próprio ser é definido por sua natureza, por sua função: o ser é o que age e é agenciado"9 (ONDÓ, 2001. p. 161). O conhecimento sobre a ética Ubuntu possibilita ao indivíduo experimentar a própria experiência humana, não de maneira individual, mas em grau comunitário, sempre se projetando em um espaço de compreensão social de forças pares.

Logo, todos os seres "compartilham a noção de que a comunidade possui três dimensões: os ancestrais, os que estão vivos e os que ainda não nasceram. A ética deve levar em consideração as três dimensões" (NOGUERA, 2011, p.148). O Ubuntu apresenta o meio pelo qual a vida humana se projeta em acréscimo a outras vidas que são sempre atreladas ao Ntu. Neste ponto não apenas as pessoas humanas compõem a humanidade, e sim tudo aquilo que interfere na movimentação das coisas, refletindo em uma humanidade interligada, um modo de ser conduzido ao movimento do ser.

Isso leva a entender que a vida terrena não depende exclusivamente dos que estão presentes, e sim é um aprendizado teórico com os que por cá estiveram e na preparação deste mundo para os que ainda vão nascer, constituindo uma noção de pessoa que difere do pensamento de formas binárias, tal pensamento não separa os seres e a comunidade. "A metafísica da filosofia ubuntu discorda, no essencial, do dogma contemporâneo da competição." (RAMOSE, 2010. p.210). A força vital do Ubuntu se concentra em uma

\footnotetext{
${ }^{8}$ como el resto de los demás animales, nace, se desarrolla y muere. Su principio vital se dobla [...] cuya unión constituye Ubuzima (unión del cuerpo con el alma) (Texto Original)

${ }^{9}$ es el denominador común que aparece en todos los seres. El ser mismo se define por su naturaleza, por su función: o ser es lo que actúa y es actuado [...] (Texto Original)
} 
comunidade humana que em esferas dinâmicas que nutre relações de interligação de espaço que comportam também conflitos e desacordos, tais ações que tangenciam a esfera do conflito são tratadas com uma nova noção de justiça: a restaurativa (CASTIANO, 2010. p. 167) ao passo que dentro da comunidade a vulnerabilidade de uma pessoa em específico também se resume a vulnerabilidade dos outros que compõem a comunidade, novamente o homo loques perpassa por toda a natureza na medida em que tudo fala, tudo age e tudo está em constante conflito.

Há ainda outro aspecto que se sublinha com sendo um valor que foi solicitado pelo espírito ubuntu. É que a reconciliação não implica evitar a confrontação entre pessoas que estiveram em campos opostos. Em outras palavras, reconciliação não significa fazer pazescom o mal, com a imoralidade, com a injustiça, com a opressão nem com o vício. Pelo contrário, reconciliação implica em exercer o dom da palavra ao seu mais alto nível, apelando para a profunda qualidade humana existente tanto no opressor como no oprimido, porque ambos precisam ser libertados da opressão. (CASTIANO, 2010. p. 166)

Nesta prerrogativa, a ética Ubuntu aparece como um convite para pensar e repensar sobre os conflitos que tangenciam a humanidade, a fim de entender o sofrimento daqueles que compõem a comunidade. Sendo o exercício da palavra uma atitude que visa reorganizar os abalos da comunidade, esta palavra pode ser concebida como Muntu, no qual este é a pessoa, constituída pelo corpo, mente, cultura e principalmente, pela palavra. A palavra com o fio condutor da sua própria história, do seu próprio conhecimento da existência. (CUNHA JUNIOR, 2010. p. 81).

Logo, a palavra também possui Ntu que serve como fundamento para a reconciliação. As pessoas da comunidade passam a se reconhecer por meio da palavra que dentro desta possui as "qualidades éticas defendidas em nome do ubuntu" (CASTIANO, 2010. p. 167). A reconciliação restaurativa é conceituada a partir de

prerrogativa de um tipo de justiça da jurisprudência tradicional africana na qual a preocupação central não é a retribuição ou a punição do infrator, mas sim e no espírito ubuntu, curar as chagas, focalizar as iniqüidades, as desigualdades, enfim, a restauração das relações e dos valores humanos quebrados. (CASTIANO, 2010. P 167)

Sendo assim, a proposta Ubuntu configura-se no fato de que ninguém nasce sozinho, mas por meio desta proposta sempre se constitui uma relação social de interdependência (NASCIMENTO, 2014. p. 2) que garante a humanidade da comunidade, tendo em visa que cada sujeito, ao nascer, já encontra uma comunidade operante; o novamente não exclui a 
existência de conflitos entre pessoas, entretanto a construtividade dos laços é operante:

A proposta de tematizar uma ética [...] através do ubuntu como modo de existir tem o intuito de produzir um futuro dentro do presente. Em outros termos, podemos viver de um modo mais solidário, aprendendo mais com os que se foram, dando aos que virão a devida importância e, sobretudo, vivendo a vida de um modo compartilhado, recuperando as férteis possibilidades que diversos povos africanos deixaram como legado e continuam reivindicando continuamente através dos mais diversos modos de existir e re-existir. Com efeito, ubuntu como modo de existir é uma re-existência [...] configura vida humana trocando experiências, solicitando laços de apoio mutuo e aprendendo sempre com os outros. (NOGUERA, 2011.p.149)

Seu predicado constitui-se em um entendimento de mundo que concerne, para si, o alcance de preservação da vida humana em que "a filosofia ubuntu-africana aparece com um horizonte teórico que dá certa consistência na justificação ontológica, epistemológica e ética para a subjectivação" (CASTIANO, 2010, p.147). Portanto, a filosofia Ubuntu é o caráter de transformação da presença do africano enquanto um ser agente e detentor de força vital que se opera dentro das relações que estão presentes na comunidade.

\section{Filosofia Ubuntu interseções entre epistemologia, ontologia e a linguagem}

Nossas reflexões sobre a Filosofia Ubuntu tomam como ponto de partida as abordagens, com já apresentado no ao decorrer do texto, do Filósofo Sul-africano Ramose. Deste ponto de análise, Ramose justifica a Filosofia Ubuntu por meio de uma lógica filosófica e por seguinte, por meio do uso da filosofia da linguagem.

Sendo assim, ao se tratar de Ubuntu como apresenta Ramose estamos sempre em diálogo que evoca a ideia de Ser e de Existência que juntas implicam em um sentido de movimento. Logo, por meio de uma investigação da linguagem - e tratando-se da linguagem como uma morada do Ser - é observável que os valores semânticos e lexicais que acompanham a palavra Ubuntu são procedidos em um campo de uma espécie de agir, uma ação que se define anterior ao agente. Aonde, a totalidade deste campo de representação do real dar-se-á, pelo o que aqui diferentemente como propõe Ramose, pelo Ntu; força-vital/força-energia/força-ação que quebra o silencio do Ser, da Existência e da própria Linguagem. Assim, podemos confirmar que Ubuntu

definido pela possibilidade de se comunicar, inserir-se, por isso, na cadeia da 
intersubjetiva e inter-relacional tanto por meio da interconexão das forças vitais, como também pelo fato de que a linguagem é um fenômeno eminentemente relacional, e com um lugar de destaque em sociedades nas quais a oralidade é central nas formas de descrição e construção de relações e de conhecimento (NASCIMENTO, 2016. p. 237).

"A existência, então, quando relacionada a Ubuntu, está sempre em um processo de desdobramento e manifestação, dinâmico e incessante" (NASCIMENTO, 2016. p. 236). Tal manifestação complexa representa uma denotação de Ubuntu que define os seres como uma parte pertencente a uma "totalidade de toda a existência seja material, espiritual e humana" (CUNHA JUNIOR, 2010. P. 89).

O exemplo que trouxemos na ajuda a definir os conceitos ontológicos e epistemológicos de Ubuntu, sendo que, segundo Ramose, a palavra Ubuntu possui em sua estrutura linguística duas outras palavras que expressam a ideia de uma existência potencializada em força.

Ubuntu é atualmente duas palavras em uma. Consiste no prefixo ubue na raiz $n t u$. Ubu evoca a ideia da existência, em geral. Abrindo-se à existência antes de manifestar a si mesmo na forma concreta ou no modo de existência de uma entidade particular. $U b u$ aberto à existência é sempre orientado para um desdobramento, que é uma manifestação concreta, incessantemente contínua, através de formas particulares e modos de ser. Neste sentido, ubu é sempre orientado para um $n t u$. Em um nível ontológico, isto não é uma separação e divisão estrita e literal entre $u b u$ e $n t u$. $U b u$ e $n t u$ não são radicalmente separáveis e realidades irreconciliavelmente opostas. Pelo contrário, são mutualmente fundadas no sentido em que são dois aspectos da existência como uma unicidade e inteireza indivisível. Portanto, $u b u$-ntu é uma categoria ontológica e epistemológica no pensamento africano do povo de língua banta. É a indivisível unicidade e inteireza da epistemologia e ontologia. Ubu é geralmente entendido como a existência e pode ser dito como uma ontologia distinta. Enquanto ntu é um ponto no qual a existência assume uma forma concreta ou um modo de ser no processo contínuo de desdobramento que pode ser epistemologicamente distinto. (RAMOSE, 1999. p. 2, grifos meus)

A reflexão de Ramose sobre os laços epistemológicos e ontológicos de Ubuntu apresenta que não há separações entre a existência das coisas e a existência da força que nutre as coisas, tais existências manifestam-se de maneira única e inseparável. Desse modo, o conhecimento sobre o ser reforça uma linguagem que se movimenta no interior das coisas e das relações que possui Ubuntu. Neste sentido, buscamos apresentar por meio da lógica a interseção que há entre a epistemologia e a ontologia. 


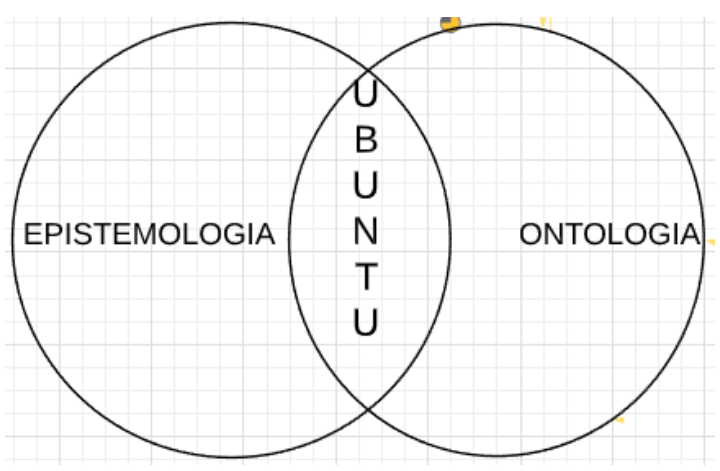

Por meio desta ilustração, e recorrendo a teoria dos conjuntos mais precisamente ao Diagrama de Venn-Euler, onde Ubuntu pertence tanto a epistemologia e a ontologia. Sendo a Epistemologia a representação do conjunto (E) e a Ontologia no conjunto (O), Ubuntu é $\mathrm{E} \cap \mathrm{O}=\mathrm{O} \cap \mathrm{E}$. Em seguida, após nossa profunda investigação sobre Ubuntu, podemos reformular a representação lógica de Ubuntu se obtermos a Ontologia como o conjunto Universo (u), isto se deve a própria natureza do Ser em estar em constante movimento e possuir na linguagem sua habitação, temos a representação a abaixo.

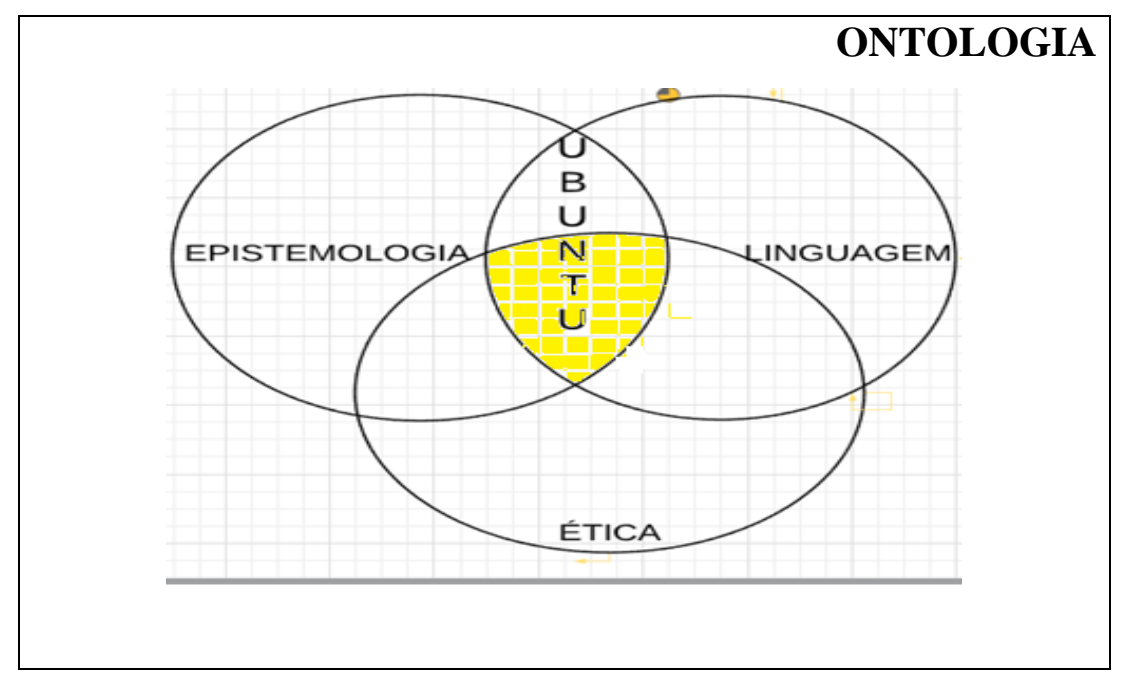

Aqui, nosso entendimento sobre a lógica filosófica Ubuntu uma especifica reflexão, tomamos a ontologia como o conjunto Universo (u), em que nele está contido tanto a epistemologia (E), a linguagem (L) e a ética (ÉT). Assim, nossa leitura do Conjunto Universo (u) é correspondente a $E \cap L \cap E ́ T=E ́ T \cap L \cap$. Entretanto, interseção que compreende a Epistemologia, a Linguagem e a Ética dar-se-á por $N t u^{10}$, força-vital. Também, podemos

10 Abordaremos em outro momento as outras analises da aplicação de Ubuntu na teoria dos conjuntos e explicaremos com mais detalhes sobre a não interseção de $U b u$ observada pelo diagrama 
observar $(\mathrm{E} \cap \mathrm{L})$ / ÉT. Onde, podemos afirmar que o alcance do conhecimento e da sabedoria em África é por meio da linguagem. Logo, a dimensão dupla e plural que abarca Ubuntu reorganiza o entendimento da existência da humanidade dos humanos que possui e são formandos por Ntu. A não divisão, o não afastamento das categorias $u b u$ e $n t u$ procede a uma não individualização do humano. Os componentes existenciais que antecedem a comunidade, neste caso, favorecem a compreensão sobre a concretude da natureza, o ser passa a não somente viver na natureza, mas entender que sua existência faz parte dela.

Fazer parte da natureza é, ao mesmo tempo, em Ubuntu, ser a natureza. Entretanto tornar-se a natureza não significa possuir um aspecto de dominação, de preponderância ou de superioridade, é uma relação que se comporta para além de uma partilha da existência, mas que consegue estabelecer elos de pertenciabialidade. Infringir a natureza pode ter consequências prejudiciais ao ser.

Esta correlação de devir a ser/natureza que surge de um não afastamento de ubu-ntu interroga a ideia moderna de que o ser o humano seria o centro do universo. Segundo Ramose

Esta ideia é, no entanto questionável, porque em toda probabilidade o universo não tem nenhum centro. Desta forma, nem mesmo como substantivo poderá fazer-se como centro do universo. A persistência teimosa e tenaz desta ideia significa que o ser humano, como um nome, é o fator causador no estabelecimento e preservação da organização social e política (RAMOSE, 1999. p. 5)

O que se traduz em seu questionamento é que o ser não pode estabelecer uma ordem imperativa sobre o universo, pois o próprio ser constitui-se com um fluxo ininterrupto que do sentido epistemológico e ontológico se faz necessário entender "o ser como vir-a-ser" (RAMOSE, 1999. p. 5). Logo, o ser que compõe Ubuntu está sempre se organizando no caos.

O ser como vir-a-ser é um diálogo imprescritível na relação $u b u$ - $n t u$, a partir de então podemos notar que o homem por não ser centro do universo, este passar ser então Muntuque, segundo Cunha Junior

MUNTU é classificação para seres dotados de inteligência. São considerados Muntu os seres humanos, vivos ou mortos. Os ancestrais e mesmo os Inquices, como ancestrais mais antigos da sociedade, estão nesta categoria de Muntu. Os animais não possuem a inteligência humana, sendo que a eles é considerada a existência de uma inteligência limitada e voltada mais para a repetição ou imitação do que a criação da inovação. No entanto, para as sociedades bantu os seres humanos e os seres animais têm em comum os sentidos da audição, visão, olfato, paladar e o sentimento. (CUNHA JUNIOR, 2010. p. 88) 
Neste sentido há muito mais coisas para além da existência dos seres humanos; este está sempre em um movimento complexo de dependência e de interdependência com a natureza apresentando um curso que vem tornar-se humanidade (MUDIMBE, 2013. p. 184). Este conceito de inteligência reitera a participação humana na totalidade do universo, isto se referência devido ao fato que os seres humanos vivos só detêm tal inteligência graças aos seres humanos mortos posto que

Os espíritos dos primeiros antepassados, muito glorificados no mundo sobrehumano, possuem um poder extraordinário, já que são os fundadores da espécie humana. Os outros mortos são apreciados à medida que aumentam e perpetuam sua força vital em sua progênie ${ }^{11}$. (TEMPELS, 2005, p. 83)

Novamente nos recorre a que não há uma centralidade do ser humano no universo, na perspectiva Ubuntu o antepassado possui um papel fundamental na constituição da comunidade, ele também está inserido na dialética do "nós", ele é também uma entidade compartilhante de $\mathrm{Ntu}$, uma existência visível e palpável que possui inteligência e, além disso, palavra. Sendo a palavra ser participante da comunidade e é parte integrante da "filosofia moral ubuntu [...] por causa do seu poder de criar a cooperação e unidade entre as pessoas”. (CASTIANO, 2010. p. 168)

Por outro lado, os animais que também são esferas de participação na comunidade são chamados de Kintu:

KINTU é uma classificação para coisa, tendo o sentido de forças do NTU não contendo inteligência e que fica a disposição dos seres humanos para propiciarmos a vida. O plural de KINTU é a palavra BINTU, ou coisas. São seres que não tem atividade própria, sendo que a idéia das atividades não é no sentido de movimento, mas sim de fazer pelo uso da inteligência que implica na capacidade de aprender criar ou executar. Vegetais, animais e substâncias como os metais são classificados como Kintu. Somente pela ação de um Muntu que os tem atividade ou transformações em outras coisas. (CUNHA JUNIOR, 2010. p. 88-89)

Isto são se resume em dizer que os animais possuam uma interiorização em relação aos humanos, mas que em graus ontológicos há uma independência entre kuntu e Muntu e

\footnotetext{
${ }^{11}$ los espíritus de los primeros antepasados, muy exaltados en el mundo sobrehumano, poseen una fuerza extraordinária dado que são os fundadores de la especie humana. los outros muertos son apreciados en la medida en que aumentan y perpetúen su fuerza vital en su progenie. (Texto Original)
} 
consequentemente uma dependência entre ambos. A ação que Muntu exerce sobre Kuntu estabelece uma relação não conflituosa, pois a Kintu também compete um agenciamento sobre Muntu, isto faz com que este último não se ponha a "objetificar a natureza" (DOMINGOS, 2011. p. 10). Há aqui uma bi-condição de existência que potencializa novamente o Ntu que possui os seres. Posto que "munthu (homem) é incontestavelmente dinâmica e ligada a natureza" (Domingos, 2011.p. 6)

Sendo assim, do ponto de vista onto-epistemologico de Ubuntu sua definição como humanidade se concentra no conceito de Ntu

Quando a essência ('ntu') é aperfeiçoada pelo grau de existência, torna-se parte da 'existência' não pode ser usada como um sinônimo de 'estar lá', uma vez que nas línguas bantu, o verbo 'ser' não possui o significado de existir. $\mathrm{O}$ oposto de existir é 'nada'. Ao analisar os elementos culturais, devemos concluir que 'nada' existe e é a entidade que se encontra na base do 'múltiplo'. Um ser é distinto do outro, porque não existe nada entre eles (KAGAME, 1971,p. 602-603 apud MUDIMBE, 2013,p. 185).

As concepções ontológicas e epistemológicas sobre Ubuntu não são dessociáveis desta raiz Ntu que projeta uma força sobre os seres, seu conteúdo representa uma arquitetura que sustenta e organiza as percepções da realidade do mundo Bantu. Ntu além de desempenhar uma força sobre os seres também é lido como uma ação divina de inferência causal na realidade, esta característica para a esfera Bantu proporciona uma compatibilidade nas relações humanas.

Ubuntu se prende em um sistema em que os fenômenos, as essências, os objetos e as sensações sobre um mundo são organizados em uma lógica particular e ao mesmo tempo plural que "somente o moderno pensamento racionalista pôde abstrair de suas formas fenomênicas" (JAHN, 1970. p. 5). Existir em/com Ubuntu é compreender à racionalidade que tal existência se manifesta na totalidade das coisas que são presentes no universo.

\section{Conclusões não finalizadas}

Mas, afinal quem é Ubuntu? Deslocamos aqui o sentido de “o que?” para “quem?”. Nessa intenção, a pergunta que fazemos nesse capitulo toma sua resposta na proposta de conceber uma filosofia Ubuntu que possua uma antecedência dos "nós". Logo, ao sabermos que a tradução de Ubuntu não é uma tarefa fácil, entendemos que neste caso Ubuntu significa humanidade (SHUTTE, 10-11 apud RAMOSE, 2002. p. 5) Ubuntu é humano, pessoa, uma 
prática do "Nós somos, porque nós somos!" " (informação verbal)

Assim, tal concepção Bantu nos projeta em uma relação muito mais presente em comunidades tradicionais que estão organizadas fora da lógica moderna de civilização, pois

Na sociedade o Ubuntu representa a existência respeitosa e equilibrada entre os seres da natureza. No Ubuntu repousa a comunidade e suas relações baseadas na tradição, na ética social e no reconhecimento de todos como indispensáveis. A identidade e personalidade dos indivíduos é parte de Ubuntu. Este Ubuntu é o conceito de totalidade nas relações humanas e nas sociedades existentes. (CUNHA JUNIOR, 2010. p. 88)

Repousar na comunidade mantém a força entre seus membros, construir alternativas em soluções próprias em meio aos conflitos. Ainda, Ubuntu é uma alternativa antirracista presente na(s) filosofia(s) africana(s) "que se mostram como um clamor do reconhecimento de humanidade e que se afirmam em uma dimensão radicalmente política" (NASCIMENTO, 2016. p. 243). Reconhecer em meio às diversidades de pessoas existes na humanidade é uma tarefa árdua e dinâmica em que lógica moderna falhou; entretanto Ubuntu é um ponto de partida para o re-entendimento dos seres humanos.

\section{Referenciais Bibliográficos}

CASTIANO, José P. Referências de Filosofia africana. Em busca da intersubjectivação. Maputo. Ndjira, 2010.

CUNHA JÚNIOR, Henrique. Ntu. Revista Espaço Acadêmico. No 108. Maio. 2010. Disponível em:< https://filosofiaafricana.weebly.com/uploads/1/3/2/1/13213792/henrique_cunha_junior_ntu. pdf> Acesso: 12 jul. 2016.

JAHN, Janheinz. Muntu: las cultura de la negritud. Trad. Daniel Romero. Madrid, 1970, p.113-122. Tradução para uso didático feita por Marcos Carvalho Lopes a partir da versão em espanhol dos dois primeiros subtítulos do "capítulo 4". Disponível em: < https://filosofiaafricana.weebly.com/uploads/1/3/2/1/13213792/ntu_filosofiaafricana_jahn.pdf> Acesso: 24 maio. 2017.

KAGAME, A. L'Ethno-Philosophie des Bantu. In: KLIBANSKY, Raymond. La Philosophie Contemporaine, , ed. Florence: La Nouva Italia, 1971. Apud MUDIMBE, V.Y. A invenção de África. Gnose, filosofia e a ordem do conhecimento. Luanda: Edições pedago, 2013.

12 NASCIMENTO, comentário feito durante a atividade (Ubuntu, uma perspectiva negra do pensamento) de estágio docente supervisionado do Programa de Pós-Graduação em Metafísica - PPGM/UnB; organizado pelo Coletivo Semeando Ubuntu da Faculdade de Educação - FE/UnB no CCN - Centro de Consciência Negra, no dia 04 de jul. 2017. 
MALOMALO, Bas'ilele. Filosofia Ubuntu: valores civilizatórios das ações afirmativas para o desenvolvimento. Curitiba: Editora CRV, 2014. MUDIMBE, V.Y. A invenção de África. Gnose, filosofia e a ordem do conhecimento. Luanda: Edições pedago, 2013.

NASCIMENTO, Alexandre do. Ubuntu como fundamento. UJIMA - Revista de Estudos Culturais e Afrobrasileiros. $N^{\circ}$ 20. Ano. 20, 2014. Disponível em: < https://filosofiaafricana.weebly.com/uploads/1/3/2/1/13213792/alexandre_do_nascimento_u buntu_como_fundamento.pdf> Acesso: 12 jul. 2016.

NASCIMENTO, Wanderson Flor do. comentário feito durante a atividade (Ubuntu, uma perspectiva negra do pensamento) de estágio docente supervisionado do Programa de PósGraduação em Metafísica - PPGM/UnB; organizado pelo Coletivo Semeando Ubuntu da Faculdade de Educação - FE/UnB no CCN - Centro de Consciência Negra, no dia 04 de jul. 2017.

NOGUERA, Renato. Ubuntu como modo de existir: Elementos gerais para uma ética afroperspectivista. Revista da ABPN.V.3 p. 147-150. 2011. Disponivel em: www.abpn.org.br/Revista/index.php/edicoes/article/viewFile/207/155. Acesso: em 23 de mar.de 2016.

OMOREGBE, Joseph. Filosofía africana: ayer y hoy.In: EZE, Emmanuel Chukwudi (Org.). Pensamiento africano. Vol. 10. Barcelona. Edicons Bellaterra, 2002.

ONDÓ, Eugenio Nkogo. Síntesis sistemática de la filosofía africana. Barcelona. Edicionescarena, 2000.

RAMOSE, Mogobe B. A ética do ubuntu. Tradução para uso didático. RAMOSE, Mogobe B. The ethics of ubuntu. In: COETZEE, Peter H.; ROUX, Abraham P.J. (eds). The African Philosophy Reader. New York: Routledge, 2002, p. 324-330, por Éder Carvalho Wen. Disponível em:< https://filosofiaafricana.weebly.com/uploads/1/3/2/1/13213792/mogobe_b._ramose_a_\%C3 \%A9tica_do_ubuntu.pdf>. Acesso: 12 jan.2018.

Mogobe B. Sobre a legitimidade e o estudo da filosofia africana. Ensaios filosóficos, Vol. IV, p. 6-23 out/2011.

, Mogobe. Globalização e ubuntu. In: SANTOS, Boaventura; MENESES, Maria Paula (Orgs.). Epistemologias do Sul. São Paulo, 2010.p.175-220.

, Mogobe B. African Philosophy through Ubuntu. Harare: Mond Books, 1999, p. 4966. Tradução para uso didático por Arnaldo Vasconcellos. Disponível em: <https://filosofiaafricana.weebly.com/uploads/1/3/2/1/13213792/texto16.pdf. > Acesso: 12 jan. 2018.

SANTOS, Boaventura de Sousa. Para além do pensamento abissal: das linhas globais a uma ecologia de saberes. In: SANTOS, Boaventura; MENESES, Maria Paula (Orgs.). Epistemologias do Sul. São Paulo, 2010, p. 31-83.

TEMPELS, Placide. Ontología bantú. In: EZE, Emmanuel Chukwudi (Org.). Pensamiento africano. Vol. 10. Barcelona.Edicons Bellaterra, 2005. 